\title{
Structural Characterization of Sulfadiazine Metabolites Using H/D Exchange Combined with Various MS/MS Experiments
}

\author{
Thomas Pfeifer \\ Metabolite Service, Radebeul, Germany \\ Jochen Tuerk \\ Institute of Energy and Environmental Technology (IUTA), Duisburg, Germany \\ Regine Fuchs \\ Waters Corporation, EU Mass Spectrometry Technologies Center, Almere, The Netherlands
}

\begin{abstract}
Two major metabolites and one minor metabolite of sulfadiazine were found in pig manure, using a special combination of different MS techniques like parent and product ion scans, H/D exchange, accurate mass measurement, and MS/MS experiments with substructures. N4acetylsulfadiazine and 4-hydroxysulfadiazine were identified as major metabolites. N4acetylsulfadiazine could be verified by $\mathrm{H} / \mathrm{D}$ exchange and comparison with product ion spectra of a synthetic reference compound. In the case of 4-hydroxysulfadiazine, the majority of possible isomers could be discounted after H/D exchange. Substructure-specific MS/MS experiments with fragment ions and comparison with product ion spectra of two references revealed the presence of 4-hydroxysulfadiazine. The minor metabolite was characterized to some degree using H/D exchange and tandem mass spectrometry in combination with a high-resolution time of flight mass spectrometer. The aminopyrimidine moiety contained an additional modification with a likely elemental composition of $\mathrm{C}_{2} \mathrm{H}_{4} \mathrm{O}$ and no further acidic hydrogen. (J Am Soc Mass Spectrom 2005, 16, 1687-1694) (C) 2005 American Society for Mass Spectrometry
\end{abstract}

I n agriculture, several classes of pharmaceuticals are used [1-2]. Antibiotics and antimicrobial agents are used for both therapeutic and prophylactic purposes in addition to their application as growth promoters. The antimicrobial sulfonamides are one class of pharmaceuticals that is widely used. As a consequence, these compounds have been found in surface and ground water, liquid manure, and soil [3-12]. After administration to animals, the majority of the pharmaceuticals used are excreted unchanged or as phase I and phase II metabolites. As part of an environmental risk assessment, these metabolites also have to be characterized because phase I metabolites can still be active against bacteria and phase II metabolites can be converted back to the parent drug or phase I metabolites. Moreover, very little is known about the capacity of microbiological decay and the occurrence of new metabolites after incubation for several months in a manure tank.

There are only a few references describing the metabolism of sulfadiazine in pigs [13, 14]. After intrave-

Published online August 11, 2005

Address reprint requests to Dr. T. Pfeifer, Metabolite Service, Wicherntrasse 5, D-01445 Radebeul, Germany. E-mail: thomas.pfeifer@elbion.de nous administration of 40 to $60 \mathrm{mg}$ sulfadiazine per $\mathrm{kg}$ body weight to male pigs without coadministration of trimethoprim, only low levels of metabolites have been observed. The N-acetyl sulfadiazine was the main metabolite in plasma. Traces of 4-hydroxysulfadiazine were also detected. $\mathrm{N}$-acetyl sulfadiazine and 4-hydroxysulfadiazine were the major metabolites in urine collected up to three hours after application. No further metabolites were identified and investigations in feces were not carried out.

The aim of the present work was to use different mass spectrometric strategies to identify possible metabolites of the widely used drug sulfadiazine in manure originating from a pig farm. The metabolites of interest should still have a similar structure as the parent drug and, therefore, retain to a greater or lesser extent their bioactive profile against micro-organisms. Earlier investigations about the biological activity of metabolites showed action of hydroxylated metabolites of sulfadiazine against different bacterial strains in contrast to $\mathrm{N}$-acetyl sulfadiazine, which showed no antimicrobial activity [15-17]. In the latter case, however, biological activity could be regained after a possible cleavage of the $\mathrm{N}$-acetyl group by microorganisms yielding the parent drug. 


\section{Experimental}

\section{Materials}

Water and acetonitrile (HPLC grade) were obtained from Baker (Deventer, The Netherlands). All other solvents (Suprasolv grade) were obtained from Merck (Darmstadt, Germany). Ammonium acetate, sodium hydroxide pellets, glacial acetic acid, formic acid, 25\% aqueous ammonia, toluene, boron tribromide, citric acid monohydrate, sodium dihydrogen phosphate dihydrate, sodium chloride, sodium hydrogen carbonate, and anhydrous sodium sulfate were of analytical grade and purchased from Merck. Sulfadiazine was purchased from Fluka (Seelze, Germany). All other substances and references were obtained from Sigma (Deisenhofen, Germany). The manure sample originated from a farm which had administered sulfadiazine to pigs two months before sampling. A total amount of 2 $\mathrm{kg}$ sulfadiazine was administered to pigs and the tank had a volume of $\sim 1000 \mathrm{~m}^{3}$.

\section{Synthesis of Metabolite $N^{4}$-Acetyl Sulfadiazine}

Sulfadiazine ( $400 \mathrm{mg}$ ) was dissolved in $25 \mathrm{~mL}$ pyridine, and $2 \mathrm{~mL}$ of acetic anhydride was added. The mixture was heated for two h at $80^{\circ} \mathrm{C}$ in a water bath. After cooling, $5 \mathrm{~mL}$ of aqueous ammonia solution $\left(25 \% \mathrm{NH}_{3}\right)$ and $5 \mathrm{~mL}$ of water were added and the mixture was allowed to react at $25^{\circ} \mathrm{C}$ for $30 \mathrm{~min}$ (hydrolysis of a side product). The resulting solution was acidified to $\mathrm{pH} 2$ with concentrated hydrochloric acid $(25 \%)$. The product was extracted twice with $200 \mathrm{~mL}$ ethyl acetate. The organic phases were collected, washed with an aqueous solution $(0.1 \%$ acetic acid), and dried over sodium sulfate. The dried ethyl acetate phase was evaporated using a rotary evaporator and the solid residue was taken up in $50 \mathrm{~mL}$ methanol. Methanol was evaporated (to remove any residual acetic acid) and the procedure was repeated twice. The residue was dried over phosphorus pentoxide. Purity was checked by HPLC $(99 \%)$, HPLC-MS, and elemental analysis $\left(\mathrm{C}_{12} \mathrm{H}_{12} \mathrm{~N}_{4} \mathrm{O}_{3} \mathrm{~S}\right.$, calculated/found: C $49.3 \% / 48.8 \%, \mathrm{H} 4.1 \% / 4.3 \%, \mathrm{~N} 19.2 \%$ / $19.0 \%$ ). The yield of $\mathrm{N}^{4}$-acetyl sulfadiazine was $45 \%$.

\section{Synthesis of Reference 5-Hydroxysulfadiazine}

To a stirred solution of $1.07 \mathrm{~g}$ 5-methoxysulfadiazine in $20 \mathrm{ml}$ dry toluene, $0.27 \mathrm{~mL}$ boron tribromide was added dropwise. The mixture was heated at $80^{\circ} \mathrm{C}$ for two $\mathrm{h}$, then allowed to stand at room-temperature and the precipitated product to filter off. The product was washed with toluene and dried carefully in vacuum. The dried residue was hydrolyzed with $0.6 \mathrm{M}$ aqueous solution of sodium hydrogen carbonate for $30 \mathrm{~min}$. The mixture was filtered and the residue dried. The yield of 5 -hydroxysulfadiazine was $40 \%$. According to NMR data, the product consisted of 50\% 5-methoxysulfadiazine and 50\% 5-hydroxysulfadiazine.

\section{Sample Preparation}

Extraction. After administration of sulfadiazine to pigs, the manure was stored in a tank at $\sim 0{ }^{\circ} \mathrm{C}$ for two months. The manure sample was homogenized for 10 min at 25,000 rpm using an ultra Turrax homogenizer (VF2/IKA, Staufen, Germany). A sample of homogenized manure $(15 \mathrm{~g})$ was weighed into a $75 \mathrm{~mL}$ centrifuge glass with a screw cap (Schott, Mainz, Germany) and $4 \mathrm{~g}$ of sodium chloride was added. The sample was buffered to $\mathrm{pH} 5.5$ by addition of $3 \mathrm{~mL}$ modified Mcllvaine buffer ( $1 \mathrm{M}$ citric acid, $1 \mathrm{M} \mathrm{Na}_{2} \mathrm{HPO}_{4}$, adjusted to $\mathrm{pH} 5.5$ with $\mathrm{NaOH}$ pellets).

Liquid-liquid extraction. The buffered manure sample was treated with $15 \mathrm{~mL}$ of a solvent mixture containing $95 \% n$-hexane and 5\% ethyl acetate (vol/vol) for lipid removal. The mixture was shaken for $15 \mathrm{~min}$ by means of a horizontal shaker from Koettermann (type 4020, Haenigsen, Germany) at $150 \mathrm{~min}^{-1}$. The phases were separated by centrifugation at $3400 \mathrm{~g}$ for $15 \mathrm{~min}$. The organic phase was removed and discarded. Sulfadiazine and metabolites were extracted twice from the aqueous phase by liquid-liquid extraction with $45 \mathrm{~mL}$ of ethyl acetate, with shaking (15 $\mathrm{min}$ ) and centrifugation (3400 $\mathrm{g}$ for $15 \mathrm{~min}$ ). The resulting ethyl acetate extracts were pooled, dried with anhydrous sodium sulfate overnight, and filtered through a paper filter. The solvent was evaporated using a rotary evaporator. The residue was reconstituted in $1 \mathrm{ml} 50 \mathrm{mM}$ ammonium acetate containing 30\% methanol and filtered through a syringe filter $(0.45 \mu \mathrm{m}$, YMC Europe, Schermbeck, Germany). The $\mathrm{pH}$ of the aqueous phase of this buffer was adjusted to $\mathrm{pH} 3.5$ by addition of acetic acid.

HPLC. Separations were performed using a Luna RP18 column ( $2 \mathrm{~mm}$ i.d., length $100 \mathrm{~mm}$, particle size 3 $\mu \mathrm{m})$ with a SafetyGuard (Phenomenex, Torrance, CA) at $30^{\circ} \mathrm{C}$. The flow rate was $0.3 \mathrm{~mL} / \mathrm{min}$. The HPLC gradient was produced by using two mobile phases. Phase A consisted of $5 \%$ acetonitrile in water $(\mathrm{vol} / \mathrm{vol})$ with $0.1 \% \mathrm{HCOOH}$ (vol/vol) and $1 \mathrm{mM}$ ammonium acetate. Phase B consisted of $0.1 \% \mathrm{HCOOH}$ (vol/vol) in pure acetonitrile. Chromatographic separation was achieved with the following gradient: $0 \mathrm{~min} 5 \% \mathrm{~B}, 5.5$ $\min 40 \%$ B, 6 min 100\% B, 8.5 min 100\% B, 9 min 5\% B, $16 \mathrm{~min} 5 \% \mathrm{~B}$. Injections of $10 \mu \mathrm{L}$ were made from each sample. The HPLC system consisted of a Perkin Elmer autosampler AS200, an Agilent HP 1100 HPLC pump, a degasser unit and a column oven (all from Agilent, Waldbronn, Germany). After HPLC separation, the individual compounds were analyzed by LC-MS/MS in positive ion mode. During H/D exchange experiments the water was replaced by $\mathrm{D}_{2} \mathrm{O}$. The solvent bottle was replaced by a smaller one with a volume of $100 \mathrm{~mL}$. Thus, a total amount of $100 \mathrm{~mL} \mathrm{D}_{2} \mathrm{O}$ was sufficient to carry out many H/D exchange HPLC runs for a full day. 


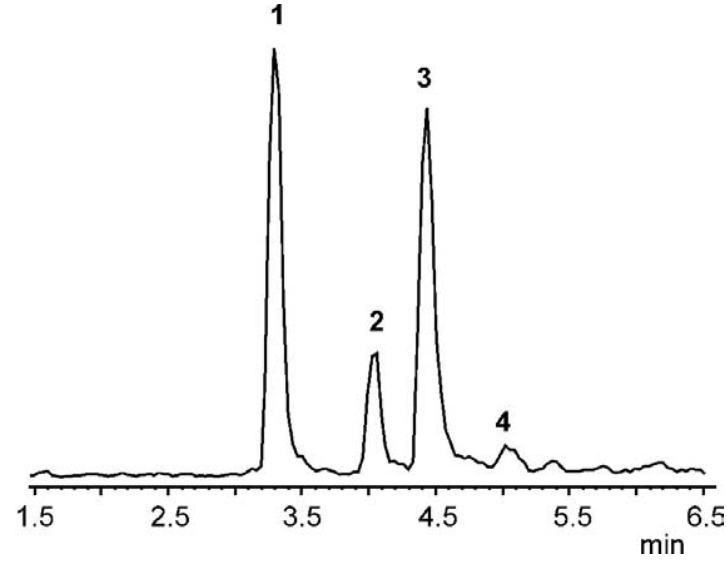

Figure 1. Precursor ion chromatogram of fragment ion $\mathrm{m} / \mathrm{z} 108$, typical of the sulfonamide moiety, at $30 \mathrm{eV}$ collision energy. The following compounds were identified: Compound 1 singly oxidized metabolite (+16 mass units); Compound 2 sulfadiazine; Compound $3 \mathrm{~N}^{4}$-acetylsulfadiazine ( +42 mass units), Compound 4 unknown metabolite with $\mathrm{m} / \mathrm{z} 295$ ( +44 mass units).

Mass Spectrometry. The triple quadrupole mass spectrometer (API 3000, Applied Biosystems, Darmstadt, Germany) was equipped with a Turbo Ionspray source and operated under the following conditions: temperature, $450{ }^{\circ} \mathrm{C}$; gas1 (nebulizer), 10; gas2 (heater), 5000 $\mathrm{L} / \mathrm{min}$; curtain gas, 10; IS voltage, $5 \mathrm{kV}$; vaporizer temperature, $450{ }^{\circ} \mathrm{C}$; DP, $60 \mathrm{~V}$; FP, $240 \mathrm{~V}$; DXP, $15 \mathrm{~V}$; CE, $30 \mathrm{eV}$; collision cell pressure, 4; collision gas nitrogen; multiplier, $2700 \mathrm{~V}$; peak width at half height, $0.7 \mathrm{Da}$. For in-source fragmentation experiments, the DP and FP were adjusted to 80 and $280 \mathrm{~V}$, respectively. The scan range for precursor ion scans was $\mathrm{m} / \mathrm{z} 100$ to 600 and collision energies of 30 and $50 \mathrm{eV}$ were utilized. The data obtained were processed by the Analyst 1.2 software. A postcolumn Valco divert valve was used to direct most of the nonsignificant LC-flow of a sample to waste. Diverting the flow minimized contamination of the MS source: $0-2 \mathrm{~min}$ divert to waste, $2-8 \mathrm{~min}$ flow to mass spectrometer, $8-16 \mathrm{~min}$ divert to waste. An additional flow of $100 \mu \mathrm{L} / \mathrm{min}$ water/acetonitrile $(50 / 50 \%$, $\mathrm{vol} / \mathrm{vol}$ ) with $0.1 \% \mathrm{HCOOH}$ compensated the missing flow from the HPLC during waste position operation. Automatic data acquisition was triggered using a contact closure signal from the autosampler.
Exact mass measurements were performed using a Micromass Q-TOF Ultima API mass spectrometer (Waters, Manchester, United Kingdom) equipped with a dual ESI source (LockSpray) operated in the positive ion mode at a resolution of 10,000 FWHM. The ammonium acetate in HPLC phase A was removed during accurate mass measurements because of a contamination interfering with the analysis of Compound 4 . The cone voltage was set at $35 \mathrm{~V}$, the capillary voltage was $3 \mathrm{kV}$, the desolvation temperature was $350{ }^{\circ} \mathrm{C}$, and the source temperature was $120^{\circ} \mathrm{C}$. Collision energy of 30 $\mathrm{eV}$ was used for all MS/MS experiments. A cluster ion of phosphoric acid was used as internal reference infused via the second probe of the LockSpray source. Data were acquired in the continuum mode from $\mathrm{m} / \mathrm{z} 50$ to 1000 with a scan time of $0.5 \mathrm{~s}$, and processed using Masslynx 4.0 software. A typical uncertainty of exact mass measurement below $\mathrm{m} / \mathrm{z} 150$ is $1.5 \mathrm{mDa}$ under standard conditions.

\section{Results and Discussion}

Parent ion scans, neutral loss scans, and informationdependant $^{\circ}$ acquisition $^{\circ}$ scans $^{\circ}\left[18^{\circ}-23\right]^{\circ}$ are $^{\circ}$ useful ${ }^{\circ}$ mass spectrometric tools to find metabolites in more or less complex matrices. During this study, we used different parent ion scans for the ethyl acetate extract and parent ion and neutral loss scans for the remaining aqueous phase after liquid/liquid extraction of manure. The discussion is focused on the results obtained from the ethyl acetate phase, since no additional metabolites (e.g., glucuronidation, sulfation) were found in the remaining aqueous phase of manure.

Characteristic fragmentation pathways of sulfonamides ${ }^{9}$ were ${ }^{\circ}$ summarized, ${ }^{\prime}$ for' instance in 'reference [24]. After collisional activation of the $[\mathrm{M}+\mathrm{H}]^{+}$ion of sulfadiazine, intense signals were observed at $\mathrm{m} / \mathrm{z}$ 92, 108 , and 156 (typical sulfonamide fragments) containing the sulfonamide moiety and at $\mathrm{m} / \mathrm{z} 96$ containing the aminopyrimidine ring. These fragment ions were used to identify potential metabolites with intact sulfonamide or aminopyrimidine moiety via precursor ion scans with the above mentioned key fragment ions. An example is shown for the precursor ion scan with fragment ${ }^{\circ}{ }^{\circ}{ }^{\circ} \mathrm{m} / \mathrm{z} 108^{\circ}$ (Figure ${ }^{\circ} 1$ ).

Table 1. Signals observed during different precursor ion scans indicating an unmodified sulfonamide (fragment ions $\mathrm{m} / \mathrm{z} 92,108$, and 156) or unmodified aminopyrimidine moiety $(\mathrm{m} / \mathrm{z}$ 96)

Signal for precursor ion scan of

\begin{tabular}{lcccccc} 
Compound & $\mathrm{RT}$ min & $\mathrm{M}+\mathrm{H}^{+} \mathrm{m} / \mathrm{z}$ & $\mathrm{m} / \mathrm{z} 92$ & $\mathrm{~m} / \mathrm{z} 108$ & $\mathrm{~m} / \mathrm{z} 156$ & $\mathrm{~m} / \mathrm{z} 96$ \\
\hline \hline 1) N-Oxide or Hydroxysulfadiazine & 3.34 & 267 & ++ & ++ & ++ & + \\
2) Sulfadiazine & 4.06 & 251 & ++ & ++ & ++ & ++ \\
3) Acetylsulfadiazine & 4.43 & 293 & - & ++ & ++ \\
4) Unknown & 5.02 & 295 & $+/-$ & + & + \\
\hline
\end{tabular}

+ Weak signal due to low concentration.

++ Good signal.

- No signal.

+ - - Very weak signal. 

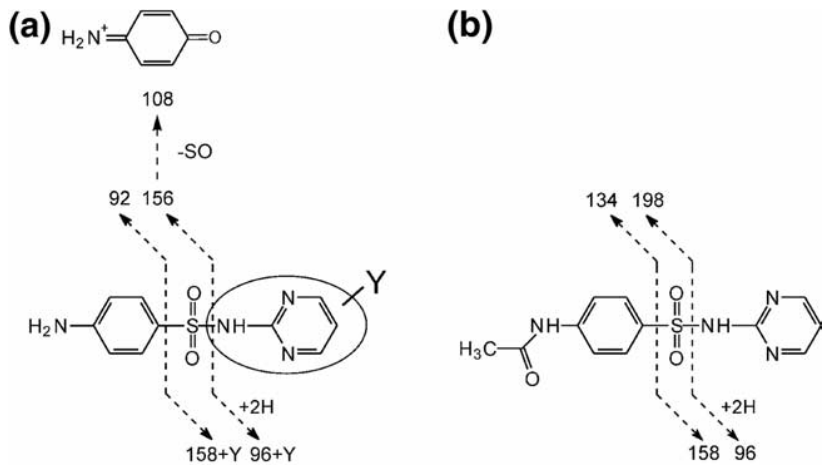

Scheme 1

The results of all precursor ion scans are summarized in ${ }^{\circ}$ Table $^{\circ} 1$. $^{\circ}$ Besides ${ }^{\circ}$ sulfadiazine, ${ }^{\circ}$ two ${ }^{\circ}$ major ${ }^{\circ}$ metabolites and one minor metabolite could be identified in the extract (Compounds 1, 3, and 4).

Potential precursor ions were identified $(\mathrm{m} / \mathrm{z} 267$, 251, 293, and 295 for the $[\mathrm{M}+\mathrm{H}]^{+}$ion), and further investigated by MS/MS. Key fragment ions of sulfadiazine and metabolites are summarized in Scheme 1. The letter $\mathrm{Y}$ indicates a possible modification of the pyrimidine moiety. Metabolites modified in the aminopyrimidine moiety showed the expected shift of the key fragment ion at $m / z 158$ and $m / z 96$ by the respective mass $(+Y)$ leading to corresponding fragment ions. An ellipse illustrates the modified part of the molecule. The product ion spectra of all identified compounds and references ${ }^{\circ}$ re $^{\circ}$ shown in ${ }^{\circ}$ Figure 2. The $^{\circ} \mathrm{MS} / \mathrm{MS}^{\circ}$ spectrum of $^{\circ}$ the $^{\circ}$ more $^{\circ}$ polar $^{\circ}$ metabolite $^{\circ}\left(\right.$ Table $^{\circ} 1,{ }^{\circ}$ Compound $^{\circ} 1$ ) showed a shift of the fragment ion with $\mathrm{m} / \mathrm{z} 96$ of sulfadiazine to $m / z 112$, but no shift of the fragment ions containing solely the sulfonamide moiety $(\mathrm{m} / \mathrm{z}$ 92, 108 and 156). The data are only in agreement with an oxidation of the aminopyrimidine group. Compound 2 could be identified as intact sulfadiazine by comparison with a reference (identical RT and MS/MS spectrum). Compound 3 showed a mass shift of +42 of all fragment ions containing the sulfonamide moiety $(\mathrm{m} / \mathrm{z} 134$, 150 , and 198), which is consistent with $\mathrm{N}^{4}$-acetyl sulfadiazine. It is interesting to note that the rearranged fragment ion at $\mathrm{m} / \mathrm{z} 108$ is also formed despite the acetylated amino group. This fragment ion is probably formed by elimination of $\mathrm{H}_{2} \mathrm{C}=\mathrm{C}=\mathrm{O}$ from the fragment ion with $m / z$ 150. A synthesized reference of $\mathrm{N}^{4}$-acetyl sulfadiazine produced identical product ion spectra and no difference in retention time during cochromatography (not shown). The most hydrophobic metabolite (Compound 4, low abundance) showed a shift of the fragment ion at $m / z 96$ (sulfadiazine) to $m / z 140$ and again no shift of fragment ions typical of the sulfonamide moiety, indicating a modification of the aminopyrimidine moiety. The fragment ion $\mathrm{m} / \mathrm{z}$ 140 is in accordance with the complementary sulfonamide fragment $m / z 156$, similar to sulfadiazine $(\mathrm{m} / \mathrm{z}$ 96) and Compound 1 ( $m / z$ 112, Scheme 1). Compared with Compound 1 , the reference 5-hydroxysulfadia-

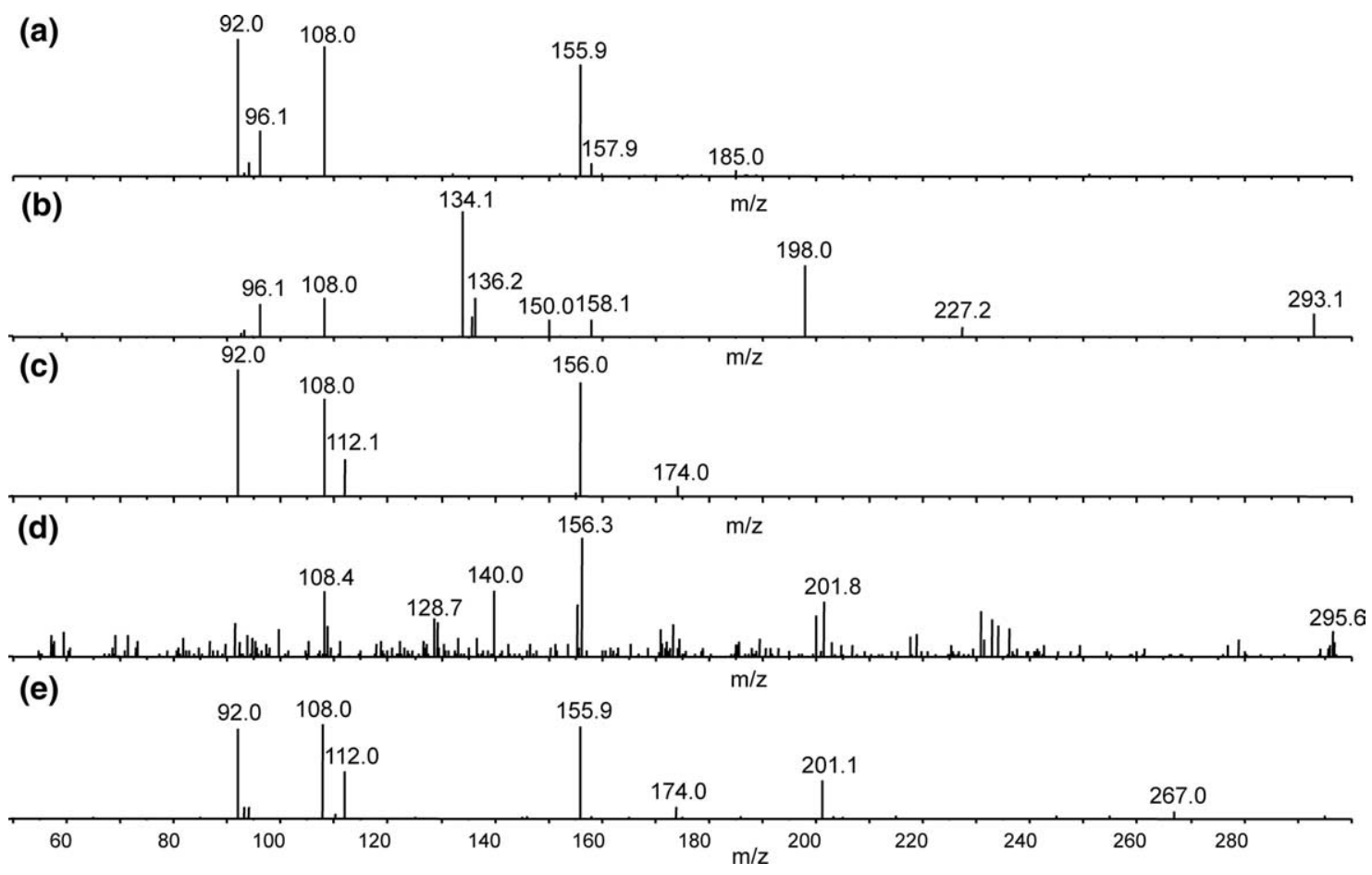

Figure 2. Product ion spectra of $[\mathrm{M}+\mathrm{H}]^{+}$ions in positive ion mode of (a) sulfadiazine, (b) acetylated metabolite, (c) singly oxidised metabolite, (d) unknown metabolite with a mass shift of +44 mass units, and (e) reference 5-hydroxysufadiazine. All spectra except for reference (e) were obtained from the purified extract. 
Table 2. Acidic protons observed for sulfadiazine and respective metabolites after changing of Mobile Phase A from water to $\mathrm{D}_{2} \mathrm{O}$

\begin{tabular}{ccc}
\hline$[\mathrm{M}+\mathrm{H}]^{+} \mathrm{m} / \mathrm{z}$ & Compound & $\begin{array}{c}\text { Number of deuterium } \\
\text { atoms incorporated, } \\
\text { without ionizing } \mathrm{D}^{+}\end{array}$ \\
\hline \hline 267 & 1 & 4 \\
251 & 2 & 3 \\
293 & 3 & 2 \\
295 & 4 & 3 \\
\hline
\end{tabular}

zine produced a very similar product ion spectrum (Figure ${ }^{\circ} 2 c^{\circ}$ and ${ }^{\circ} \mathrm{e}$ ). ${ }^{\circ}$ However, ${ }^{\circ}$ the ${ }^{\circ}$ fragment ${ }^{\circ}$ ion $^{\circ}$ at ${ }^{\circ} \mathrm{m} / \mathrm{z}$ 201 resulting from a rearrangement $\left(\mathrm{M}+\mathrm{H}^{+}-\right.$ $\mathrm{H}_{2} \mathrm{SO}_{2}$ ) was only observed for the reference compound and both compounds showed different retention behavior on RP 18 HPLC (RT reference $3.9 \mathrm{~min}$, RT metabolite $3.34 \mathrm{~min}$ ). Unfortunately, many questions remained about the position of oxidation of this most polar metabolite and the nature of the less abundant metabolite (Compound 4).

\section{H/D Exchange}

Knowing the number of acidic hydrogens indicated by $\mathrm{H} / \mathrm{D}$ exchange experiments is a great advantage during structure elucidation. Surprisingly, this method has infrequently been applied for characterization of metabolites ${ }^{\circ}[25-33]{ }^{\circ}$ The ${ }^{\circ}$ higher ${ }^{\circ} \operatorname{cost}^{\circ}{ }^{\circ}{ }^{\circ} \mathrm{D}_{2} \mathrm{O}$ could be considered a certain drawback, but the consumption of $\mathrm{D}_{2} \mathrm{O}$ can be significantly reduced by using smaller columns and smaller solvent bottles. Alternatively, fractions can be collected and redissolved in $\mathrm{D}_{2} \mathrm{O}$ containing solvents.

$\mathrm{H} / \mathrm{D}$ exchange needs no reference compounds and is useful in differentiation of $\mathrm{S}$ or $\mathrm{N}$ oxides resulting in no mass shift, and hydroxylation of $C$ atoms leading to a shift of one mass unit after incorporation of one deuterium atom at the newly formed hydroxy group. Moreover, the presence of adducts with sodium or ammonium could be observed, which is sometimes useful in the verification of the unfragmented molecular ion. $\mathrm{H} / \mathrm{D}$ exchange experiments were performed during this study to reduce the number of possible structural
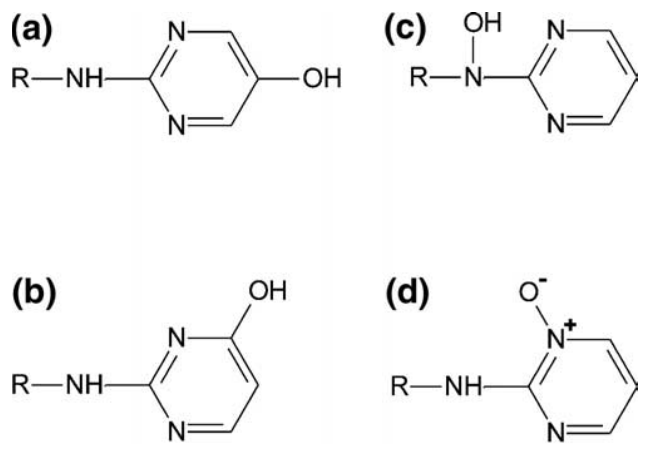

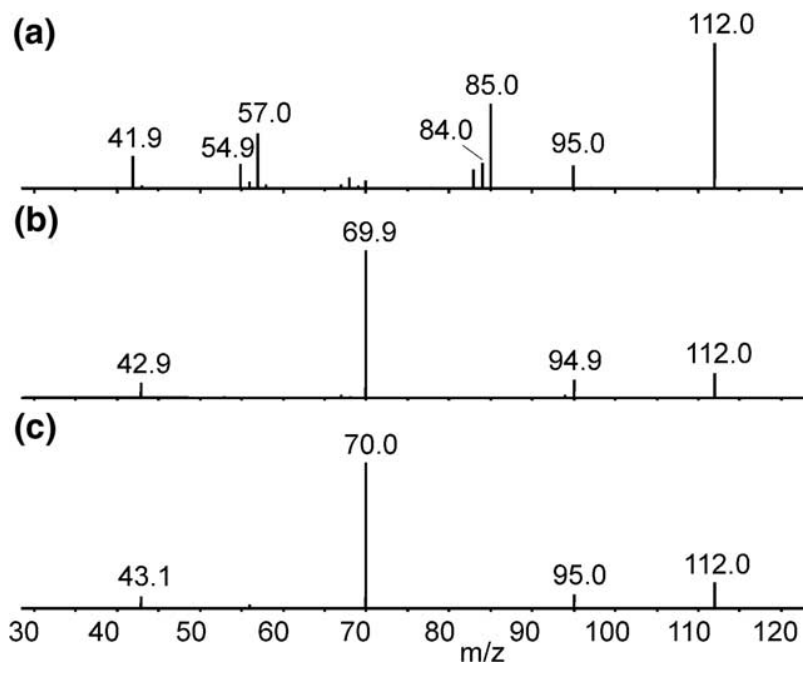

Figure 3. Comparison between product ion spectra of (a) reference 5-hydroxy-2-aminopyrimidine, (b) reference compound 4-hydroxy-2-aminopyrimidine, and (c) the in source formed fragment ion with $\mathrm{m} / \mathrm{z} 112$ of the hydroxy metabolite.

isomers for Compound 1. These experiments were also very helpful to confirm the metabolite $\mathrm{N}^{4}$-acetylsulfadiazine and to get more insight into the structure of the minor Compound 4.

When $\mathrm{D}_{2} \mathrm{O}$ is used as mobile phase instead of water, a $[\mathrm{M}+\mathrm{D}]^{+}$ion is formed in positive ion mode with additional exchange of all acidic hydrogens in the molecule by deuterium. The observed mass shifts of all compounds after chromatography of the extracts with $\mathrm{D}_{2} \mathrm{O}^{\circ}$ were ${ }^{\circ}$ summarized ${ }^{\circ}$ in Table 2 . ${ }^{\circ}$ Sulfadiazine ${ }^{\circ}$ showed an expected incorporation of three deuterium atoms (two at the amino group, one at the $-\mathrm{SO}_{2} \mathrm{NH}$ - moiety). Compound 4 showed also an incorporation of three deuterium atoms. Together with the information from the MS/MS spectrum, revealing an intact sulfonamide group, it was proven that there was no further incorporation of an acidic hydrogen (no hydroxylation) compared with sulfadiazine. The product ion spectrum of deuterated Compound 4 (not shown) resulted in a shift of fragment ion $\mathrm{m} / \mathrm{z} 140$ to 143 , in accordance with three deuterium atoms at the amino moiety similar to the fragment ion $\mathrm{m} / \mathrm{z} 96$ of sulfadiazine (shift to $\mathrm{m} / \mathrm{z} 99$, Scheme 1). Acetylsulfadiazine incorporated only two deuterium atoms, one at the acetylated amino group and one at the $-\mathrm{SO}_{2} \mathrm{NH}$ - group as expected.
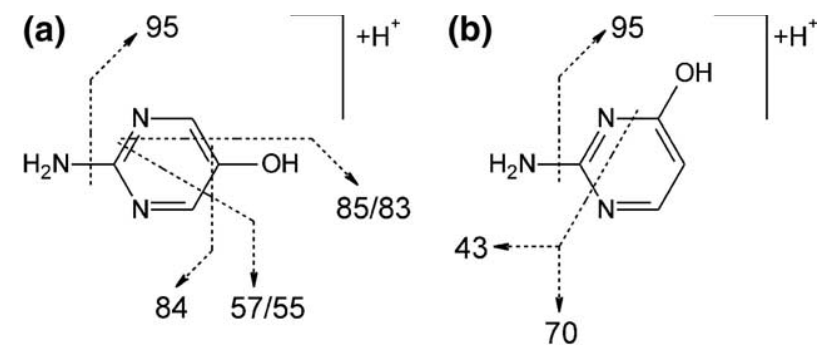


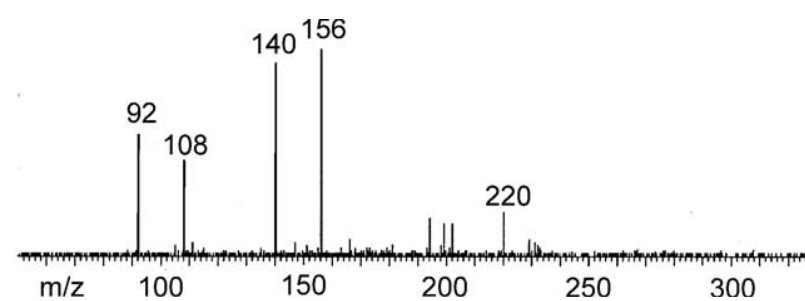

Figure 4. Time-of-flight product ion spectrum of Compound 4 at $30 \mathrm{eV}$ collision energy.

Compound 1 showed a mass shift of 16 mass units compared with sulfadiazine and was consistent with an oxidation product. On the basis of MS/MS spectra, several hydroxylation, $\mathrm{N}$-oxide (Scheme 2) or less likely epoxide products were possible. To distinguish between these many isomers, $\mathrm{H} / \mathrm{D}$-exchange experiments were also performed. The metabolite showed an incorporation of four deuterium atoms, two at the amino group, one at the $-\mathrm{SO}_{2} \mathrm{NH}$ - group, and an additional one in accordance with a hydroxy function. Thus, the obtained data were only consistent with the two hydroxy pyrimidine isomers in Scheme 2. The other two $\mathrm{N}$-oxidized isomers could be excluded, because in these cases, incorporation of one deuterium less would be expected. An alternative $\mathrm{N}$-oxide could also be proven by APCI-MS, producing a distinct $[\mathrm{M}+\mathrm{H}-\mathrm{O}]^{+}$ion due $^{\circ}$ to $^{\circ}$ decomposition ${ }^{\circ}{ }^{\circ}{ }^{\circ}$ the $^{\circ}$ ion $^{\circ}$ source $^{\circ}\left[34^{\circ}-36\right]^{\circ} .{ }^{\circ}$ In ${ }^{\circ}$ the case of 4- or 5-hydroxysulfadiazine, however, this ion would not be observed.

\section{Substructure-Specific Fragmentation}

After $\mathrm{H} / \mathrm{D}$ exchange experiments, two hydroxy isomers remained as possible structures for Compound 1 (Scheme $\mathbf{2 a}$ and $\mathbf{b}$ ). To distinguish between the two isomers a substructure specific MS/MS approach was applied. To this end, the two possible substructures 4and 5-hydroxy-2-aminopyrimidine which could be purchased were analyzed by LC-MS/MS. The resulting

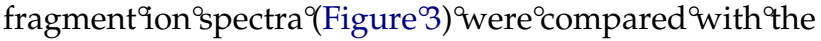
spectrum produced by in-source fragmentation. The proposed fragmentation of the two reference compounds 5-hydroxy-2-aminopyrimidine and 4-hydroxy2-aminopyrimidine is illustrated in Scheme 3. From the

Table 3. Determined exact masses for intense fragment ions of the minor Compound 4 . The mass of the electron missing for positive charged ions was not considered

\begin{tabular}{lccc}
\hline $\begin{array}{l}\text { Elemental } \\
\text { composition }\end{array}$ & $\begin{array}{c}\text { Error } \\
(\mathrm{ppm})\end{array}$ & $\begin{array}{c}\text { Determined } \\
\text { mass }\end{array}$ & $\begin{array}{c}\text { Theoretical } \\
\text { mass }\end{array}$ \\
\hline \hline C6H6NO2S & -1.4 & 156.0117 & 156.0119 \\
C6H10N3O & 11.5 & 140.0840 & 140.0824 \\
C6H6NO $^{\mathrm{a}}$ & 8.0 & 108.0458 & 108.0449 \\
${\mathrm{C} 6 \mathrm{H} 6 \mathrm{~N}^{\mathrm{a}}}^{\mathrm{a}}$ & 1.9 & 92.0502 & 92.0500 \\
\hline
\end{tabular}

${ }^{\mathrm{a}} \mathrm{F}$ ragment ions with an asterisk are typical sulfonamide fragments. An intense fragment ion with $\mathrm{m} / \mathrm{z} 92$ was only observed at $30 \mathrm{eV}$ with the TOF-MS instrument but not with the triple quadrupole.

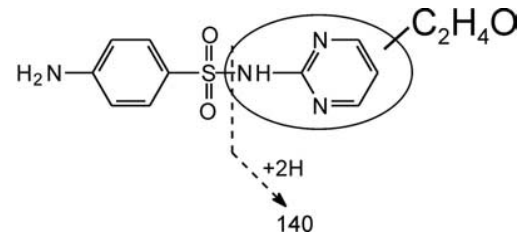

Scheme 4

subsequent MS/MS analysis of the fragment ion $\mathrm{m} / \mathrm{z}$ 112 (containing one of the two possible hydroxyaminopyrimidins), only one reference and the primary fragment ion of the metabolite produced an identical MS/MS spectrum. According to the MS/MS spectra, the fragment ion substructure of the hydroxy metabolite was only in agreement with 4-hydroxy-2-aminopyrimidine. This technique was particularly useful because only a small part of the metabolite structure was necessary as reference. Moreover, the smaller molecule produced a more specific fragmentation pattern with respect to the modified part of the molecule. This property was attributable to the more effective transfer of energy to the molecule with a lower number of degrees of freedom. Thus, fragment ions were observed for substructures that could not be obtained from the intact $^{\circ}$ metabolite $^{\circ}\left(\right.$ Figure $\left.^{\circ} 2\right),{ }^{\circ}$ even $^{\circ}{ }^{\circ}{ }^{\circ}$ the $^{\circ}$ case $^{\circ}$ of ${ }^{\circ}$ higher collision energy.

The $^{\circ}$ nature ${ }^{\circ}$ of $^{\circ}$ the ${ }^{\circ}$ minor $^{\circ}$ metabolite $^{\circ}$ could $^{\circ}$ not $^{\circ}$ be determined unequivocally. An exact mass of the intact molecule could be determined with a high-resolution time of flight mass spectrometer. The obtained value for $\mathrm{M}+\mathrm{H}^{+}$(295.0877) is in agreement with the proposed elemental composition C12H15N4O3S (theoretical mass $=295.0865$, error $4.1 \mathrm{ppm}$, see below). By applying MS $/$ MS $^{\circ}$ (Figure ${ }^{\circ} 4$ ), ${ }^{\circ}$ an $^{\circ}$ accurate $^{\circ}$ mass $^{\circ}$ could $^{\circ}$ also $^{\circ}$ be obtained for the fragment ion at $\mathrm{m} / \mathrm{z} 140$, containing the modification $(\mathrm{m} / \mathrm{z} 96+44)$. Within the obtained mass accuracy (about $1.5 \mathrm{mDa}$ below $\mathrm{m} / \mathrm{z} 150$ ) a likely elemental ${ }^{\circ}$ composition $^{\circ}$ for $^{\circ} Y^{\circ}{ }^{\circ}$ could ${ }^{\circ} \mathrm{be}^{\circ}$ determined. Table 3 displays the determined mass accuracy and most likely elemental compositions for intense key fragment ions of the minor metabolite. At $30 \mathrm{eV}$ collision energy, an intense fragment ion with $\mathrm{m} / \mathrm{z} 92$ was only observed with ${ }^{\circ}$ the ${ }^{\circ}$ TOF-MS $^{\circ}\left(\text { Figure }^{\circ} 4\right)^{\circ}$ but $^{\circ}$ not $^{\circ}$ with $^{\circ}$ the ${ }^{\circ}$ triple quadrupole ${ }^{\circ}$ (Figure $\left.{ }^{\circ} 2 \mathrm{~d}\right)^{\circ}{ }^{\circ}$ which $^{\circ}$ is ${ }^{\circ}$ probably ${ }^{\circ}$ attributable to a higher activation of the $\mathrm{M}+\mathrm{H}^{+}$ion in the QTOF collision cell and the better sensitivity of TOF MS. Because of these different experimental conditions, the fragment ion $\mathrm{m} / \mathrm{z} 140$ was one of the most abundant fragments in the QTOF product ion spectrum of Com-

Table 4. Possible elemental compositions for fragment ion $\mathrm{m} / \mathrm{z}$ 140 of Compound 4

\begin{tabular}{lccc}
\hline $\begin{array}{l}\text { Elemental } \\
\text { composition }\end{array}$ & $\begin{array}{c}\text { Error } \\
(\mathrm{ppm})\end{array}$ & $\begin{array}{c}\text { Theoretical } \\
\text { mass }\end{array}$ & $\begin{array}{c}\text { Double bond } \\
\text { equivalents }\end{array}$ \\
\hline \hline C4H8N6 & 21.4 & 140.0810 & 4 \\
C6H10N30 & 11.4 & 140.0824 & 3.5 \\
C8H12O2 & 2.1 & 140.0837 & 3 \\
\hline
\end{tabular}


pound 4 in contrast to the triple quadrupole spectrum. It must be emphasized that the obtained spectrum of Compound 4 had a very low signal to noise ratio. Therefore, the mass tolerance was slightly increased compared with the standard performance of the mass spectrometer (see Experimental). The following general parameters were utilized: odd and even electron ions; RDBE, -0.5 to 30 ; number of carbon atoms, 0 to 25; number of hydrogen atoms, 0 to 50 ; number of nitrogen atoms, 0 to 10; number of oxygen atoms, 0 to 10; number of sulphur atoms, 0 to 2; tolerance $3.5 \mathrm{mDa}$ (25 ppm, ACD 7.0 ver. 7.08, Toronto, Canada). The most likely elemental composition was $\mathrm{C} 6 \mathrm{H} 10 \mathrm{~N} 3 \mathrm{O}$ with an odd number of electrons leading to a residual composition of $^{\circ} \mathrm{OC} 2 \mathrm{H}^{\circ}{ }^{\circ}$ for $^{\circ} \mathrm{Y}^{\circ}\left(\mathrm{Scheme}^{\circ} 4\right) .^{\circ} \mathrm{Table}^{\circ} 4^{\circ}$ summarizes ${ }^{\circ}$ other less likely elemental compositions. Together with the $\mathrm{H} / \mathrm{D}$ experiments it was clear that the modification contained $^{\circ}$ no $^{\circ}$ hydroxy $^{\circ}$ group $^{\circ}\left(\right.$ Table $\left.^{\circ} 2\right) .^{\circ} \mathrm{A}^{\circ}$ possible structure of this minor metabolite is shown in Scheme 4. Several different combinations are possible; e.g., formation of an ethoxy moiety or a combination of methylation and formation of a methoxy moiety. However, this is only an assumption. Quite unusual metabolites might be formed because an incubation of the drug and metabolites took place for two months under reductive microbial conditions.

\section{Conclusions}

Two major metabolites and one minor metabolite of sulfadiazine were found in pig manure using a combination of different MS techniques. The minor metabolite was characterized to some degree using H/D exchange and LC-MS/MS in combination with a high-resolution time of flight mass spectrometer. The aminopyrimidine moiety contained an additional modification with a likely elemental composition of $\mathrm{C}_{2} \mathrm{H}_{4} \mathrm{O}$ and no further acidic hydrogen. $\mathrm{N}^{4}$-acetylsulfadiazine and 4hydroxysulfadiazine were identified as major metabolites in manure; 5-hydroxysulfadiazine has also been described ${ }^{\circ}$ in $^{\circ}$ different $^{\circ}$ animals $^{\circ}\left[16,{ }^{\circ} 37,{ }^{\circ} 38\right]^{\circ}$ but ${ }^{\circ}$ could $^{\circ}$ be excluded using a substructure specific MS/MS approach with primary fragment ions containing the modified part of the compound. Moreover, further possible oxidation products could be discounted using $\mathrm{H} / \mathrm{D}$ exchange experiments, reducing the number of necessary reference compounds. In this case, the combination of $\mathrm{H} / \mathrm{D}$ exchange and substructure specific MS/MS experiments was especially useful. The environmental relevance of the results was underlined by the fact that $\mathrm{N}^{4}$-acetylsulfadiazine, a phase II metabolite, was already found in pig manure in higher concentrations ${ }^{\circ} \operatorname{than}^{\circ}$ the $^{\circ}$ administered $^{\circ}$ parent $^{\circ}$ drug $^{\circ}[7]$.

\section{Acknowledgments}

The authors gratefully acknowledge support of this research by Kai Bester who organized the cooperation with pig farmers.

\section{References}

1. Halling-Sørensen, B.; Nors Nilsen, S.; Lanzky, P. F.; Ingerslev, F.; Holten-Lützhoft, H. C.; Jørgensen, S. E. Occurrence, fate, and effects of pharmaceutical substances in the environment-A review. Chemosphere. 1998, 36, 357.

2. Kuemmerer, K. Pharmaceuticals in the environment. Sources, fate, effects, and risks; Kuemmerer, K., Ed.; 2nd ed.; Vol. XXXI. Springer Publishing: Berlin, Germany, 2004.

3. Hirsch, R.; Ternes, T. A.; Haberer, K.; Mehlich, A.; Ballwanz, F.; Kratz, K. L. Determination of antibiotics in different water compartments via liquid chromatography-electrospray tandem mass spectrometry. J. Chromatogr. A. 1998, 815(2), 213223.

4. Hartig, C.; Storm, T.; Jeckel, M. Detection and identification of sulphonamide drugs in municipal waste water by liquid chromatography coupled with electrospray ionization tandem mass spectrometry. J. Chromatogr. A 1999, 854, 163-173.

5. Hirsch, R.; Ternes, T. A.; Haberer, K.; Kratz, K. L. Occurrence of antibiotics in the aquatic environment. Sci. Total Environ. 1999, 225, 10.

6. Lindsey, M. E.; Meyer, T. M.; Thurman, E. M. Analysis of trace levels of sulfonamide and tetracycline antimicrobials in groundwater and surface water using solid-phase extraction and liquid chromatography/mass spectrometry. Anal. Chem. 2001, 73(19), 4640-4646.

7. Pfeifer, T.; Tuerk, J.; Bester, K.; Spiteller, M. Determination of selected sulfonamide antibiotics and trimethoprim in manure by electrospray and atmospheric pressure chemical ionization tandem mass spectrometry. Rapid Commun. Mass Spectrom. 2002, 16(7), 663-669.

8. Haller, M. Y.; Muller, S. R.; McArdell, C. S.; Alder, A. C.; Suter, M. J. Quantification of veterinary antibiotics (sulfonamides and trimethoprim) in animal manure by liquid chromatography-mass spectrometry. J. Chromatogr. A 2002, 952(1/2), 111-120.

9. Campagnolo, E. R.; Johnson, K. R.; Karpati, A.; Rubin, C. S.; Kolpin, D. W.; Meyer, M. T.; Esteban, J. E.; Currier, R. W.; Smith, K.; Thu, K. M.; McGeehin, M. Antimicrobial residues in animal waste and water resources proximal to large-scale swine and poultry feeding operations. Sci. Total Environ. 2002, 299(1/3), 89-95.

10. Mueller, S. R.; Singer, H.; Stoob, K.; Burkhardt, M.; Hartmann, N.; Goetz, C.; Stamm, C.; Waul, C. Occurrence and fate of antibiotics in manure, soil, and water. Mitt. Lebensm. Hyg. 2003, 94(6), 574-578.

11. Miao, X. S.; Bishay, F.; Chen, M.; Metcalfe, C. D. Occurrence of antimicrobials in the final effluents of wastewater treatment plants in Canada. Environ. Sci. Technol. 2004, 38(13), 3533-3541.

12. Yang S.; Cha J.; Carlson, K. Quantitative determination of trace concentrations of tetracycline and sulfonamide antibiotics in surface water using solid-phase extraction and liquid chromatography/ion trap tandem mass spectrometry. Rapid Commun. Mass Spectrom. 2004, 18(18), 2131-2145.

13. Nouws, J. F.; Mevius, D.; Vree, T. B.; Degen, M. Pharmacokinetics and renal clearance of sulfadimidine, sulfamerazine, and sulfadiazine and their N4-acetyl and hydroxy metabolites in pigs. Vet. $Q$ 1989, 11(2), 78-86.

14. Nielsen, P.; Friis, C.; Gyrd-Hansen, N.; Rasmussen, F. Metabolism of sulfadiazine in neonatal and young pigs. Comparative in vivo and in vitro studies. Biochem. Pharmacol. 1986, 35(15), 2509-2512.

15. Nouws, J. F.; Vree, T. B.; Hekster, Y. A. In vitro antimicrobial activity of hydroxy and N4-acetyl sulphonamide metabolites. Vet. Q 1985, 7(1), 70-72.

16. Woolley, J. L.; Sigel, C. W. Metabolism and disposition by the rat of ${ }^{35} \mathrm{~S}$-sulfadiazine alone and in the presence of thrimethoprim. Drug Metab. Dispos. 1979, 7(2), 94-99. 
17. Schoondermark-van de Ven, E.; Vree, T.; Melchers, W.; Camps, W.; Galama, J. In vitro effects of sulfadiazine and its metabolites alone and in combination with pyrimethamine on Toxoplasma gondii. Antimicrob. Agents Chemother. 1995, 39(3), 763-765.

18. Xia Y. Q.; Miller, J. D.; Bakhtiar, R.; Franklin R. B.; Liu, D. Q. Use of a quadrupole linear ion trap mass spectrometer in metabolite identification and bioanalysis. Rapid Commun. Mass Spectrom. 2003, 17(11), 1137-1145.

19. Hopfgartner, G.; Husser, C.; Zell, M. Rapid screening and characterization of drug metabolites using a new quadrupolelinear ion trap mass spectrometer. J. Mass Spectrom. 2003, 38(2), 138-150.

20. Anari, M. R.; Sanchez, R. I.; Bakhtiar, R.; Franklin, R. B.; Baillie, T. A. Integration of knowledge-based metabolic predictions with liquid chromatography data-dependent tandem mass spectrometry for drug metabolism studies: Application to studies on the biotransformation of indinavir. Anal. Chem. 2004, 76(3), 823-832.

21. Ramanathan, R.; McKenzie, D. L.; Tugnait, M.; Siebenaler, K. Application of semi-automated metabolite identification software in the drug discovery process for rapid identification of metabolites and the cytochrome P450 enzymes responsible for their formation. J. Pharm. Biomed. Anal. 2002, 28(5), 945-951.

22. Lim, H. K.; Stellingweif, S.; Sisenwine, S.; Chan, K. W. Rapid drug metabolite profiling using fast liquid chromatography, automated multiple-stage mass spectrometry, and receptorbinding. J. Chromatogr. A 1999, 831(2), 227-241.

23. Tiller, P. R.; Land, A. P.; Jardine, I.; Murphy, D. M.; Sozio, R.; Ayrton, A.; Schaefer, W. H. Application of liquid chromatography-mass spectrometry(n) analyzes to the characterization of novel glyburide metabolites formed in vitro. J. Chromatogr. A 1998, 794(1/2), 15-25.

24. Klagkou, K.; Pullen, F.; Harrison, M.; Organ, A.; Firth, A.; Langley, G. J. Fragmentation pathways of sulphonamides under electrospray tandem mass spectrometric conditions. Rapid Commun. Mass Spectrom. 2003, 17(21), 2373-2379.

25. Ohashi, N.; Furuuchi, S.; Yoshikawa, M. Usefulness of the hydrogen-deuterium exchange method in the study of drug metabolism using liquid chromatography-tandem mass spectrometry. J. Pharm. Biomed. Anal. 1998, 18(3), 325-334.

26. Gianelli, L.; Mellerio, G. G.; Siviero, E.; Rossi, A.; Cabri, W.; Sogli, L. Mass spectrometry of avermectins: Structural determination of two new derivatives of Ivermectin B(1a). Rapid Commun. Mass Spectrom. 2000, 14(14), 1260-1265.

27. Olsen, M. A.; Cummings, P. G.; Kennedy-Gabb, S.; Wagner, B. M.; Nicol, G. R.; Munson, B. The use of deuterium oxide as a mobile phase for structural elucidation by HPLC/UV/ESI/ MS. Anal. Chem. 2000, 72(20), 5070-5078.

28. Liu, D. Q.; Hop, C. E.; Beconi, M. G.; Mao, A.; Chiu, S. H. Use of on-line hydrogen/deuterium exchange to facilitate metab- olite identification. Rapid Commun. Mass Spectrom. 2001, 15(19), 1832-1839.

29. Blum, W.; Aichholz, R.; Ramstein, P.; Kuhnol, J.; Bruggen, J.; O'Reilly, T.; Florsheimer, A. In vivo metabolism of epothilone $B$ in tumor-bearing nude mice: Identification of three new epothilone B metabolites by capillary high-pressure liquid chromatography/mass spectrometry/tandem mass spectrometry. Rapid Commun. Mass Spectrom. 2001, 15(1), 41-49.

30. Lam, W.; Ramanathan, R. In ectrospray ionization source hydrogen/deuterium exchange LC-MS and LC-MS/MS for characterization of metabolites. J. Am. Soc. Mass Spectrom. 2002, 13(4), 345-353.

31. Blum, W.; Buhl, T.; Altmann, E.; Kuhnol, J.; Ramstein, P.; Aichholz, R. Complementary use of ion trap/time-offlight mass spectrometry in combination with capillary highpressure liquid chromatography: Early characterization of in vivo metabolites of the cathepsin $\mathrm{K}$ inhibitor NVP-AAV490 in rat. J. Chromatogr. B, Biomed. Appl. 2003, 787(2), 255-270.

32. Nassar, A. E. Online hydrogen-deuterium exchange and a tandem-quadrupole time-of-flight mass spectrometer coupled with liquid chromatography for metabolite identification in drug metabolism. J. Chromatogr. Sci. 2003, 41(8), 398-404.

33. Edlund, P. O.; Baranczewski, P. Identification of BVT. 2938 metabolites by LC/MS and LC/MS/MS after in vitro incubations with liver microsomes and hepatocytes. J. Pharm. Biomed. Anal. 2004, 34(5), 1079-1090.

34. Ramanathan, R.; Su, A. D.; Alvarez, N.; Blumenkrantz, N.; Chowdhury, S. K.; Alton, K.; Patrick, J. Liquid chromatography/mass spectrometry methods for distinguishing $\mathrm{N}$-oxides from hydroxylated compounds. Anal. Chem. 2000, 72(6), 13521359.

35. Tong, W.; Chowdhury, S. K.; Chen, J. C.; Zhong, R.; Alton, K. B.; Patrick J. E. Fragmentation of N-oxides (deoxygenation) in atmospheric pressure ionization: Investigation of the activation process. Rapid Commun. Mass Spectrom. 2001, 5(22), 2085-2090.

36. Dilrukshi, M. P.; Wing, L.; Steven, M.; Ramanathan, R. Distinguishing N-oxide and hydroxyl compounds: Impact of heated capillary/heated ion transfer tube in inducing atmospheric pressure ionization source decompositions. J. Mass Spectrom. 2004, 39, 600-606.

37. Vree, T. B.; Schoondermark-van de Ven, E.; Verwey-van Wissen, C. P.; Bars, A. M.; Swolfs, A.; van Galen, P. M.; Amatdjais-Groenen, $\mathrm{H}$. Isolation, identification, and determination of sulfadiazine and its hydroxy metabolites and conjugates from man and Rhesus monkey by high-performance liquid chromatography. J. Chromatogr. B, Biomed. Appl. 1995, 670(1), 111-123.

38. Nouws, J. F.; Firth, E. C.; Vree, T. B.; Baakman, M. Pharmacokinetics and renal clearance of sulfamethazine, sulfamerazine, and sulfadiazine and their N4-acetyl and hydroxy metabolites in horses. Am. J. Vet. Res. 1987, 48(3), 392-402. 